\title{
Using social norms in smart meters: the norm distance effect
}

\author{
Magnus Bergquist • Andreas Nilsson
}

Received: 30 June 2016 / Accepted: 18 June 2018 / Published online: 25 July 2018

(C) The Author(s) 2018

\begin{abstract}
Normative feedback has shown to promote energy conservation, indicating that people are motivated to adjust their energy usage to others. Yet, the effect of social norms is conditional. Adding to past research, we proposed a norm distance effect, hypothesizing that the influential power of social norms increases as others' behavior comes closer to peoples' own behavior. In two experiments, we provided participants with normative information on energy usage through fictive smart phone applications. Results first conceptually replicated the norm alignment effect, showing that participants adjusted their energy usage intentions more when other peoples engaged in the approved rather than the disapproved behavior. In line with our norm distance hypothesis, both experiments found that people are more likely to adjust their behavior intentions to others as others' behaviors come closer to their own behavior. These experiments contribute to past research on normative influence through smart meters, suggesting that norm distance can refine normative feedback promoting energy conservation.
\end{abstract}

Keywords Using social norms in smart meters .

The norm distance effect

\footnotetext{
M. Bergquist $(\bowtie) \cdot$ A. Nilsson

Department of Psychology, University of Gothenburg, PO Box

500, 40530 Göteborg, Sweden

e-mail: magnus.bergquist@psy.gu.se
}

\section{Introduction}

Energy production is dominated by fossil fuels causing substantial $\mathrm{CO}_{2}$ emissions. Twenty percent of these emissions are due to residential energy consumption (OECD/IEA 2016), making peoples household energy behavior a noteworthy aspect of environmental impact. Still, past research suggests that every day individual behavioral change, with little or no decrease in wellbeing, can lessen these emissions by $20 \%$ (Dietz et al. 2009). How should interventions to motivate such energy conservation behaviors be designed? A number of intervention techniques have shown to effectively reduce energy usage (see Abrahamse et al. 2005 for review). For example, by providing feedback (Karlin et al. 2015) or by using social influence approaches (Abrahamse and Steg 2013), one particularly successful social influence technique is normative feedback (e.g., Allcott 2011; Schultz et al. 2007). Normative feedback draws on the persuasive impact of the social norms, that is, the perceived behavioral pattern and/or (dis)approval by others (Cialdini et al. 1990). More formally, social norms have been defined as "rules and standards that are understood by members of a group, and that guide and/ or constrain social behavior without the force of law" (Cialdini and Trost 1998, pp. 152) and have metaphorically been described as navigation tool steering behavior in a socially appropriate direction (Morris et al. 2015). Past research has shown that social norms can be used to promote a number of pro-environmental behaviors such as littering prevention (Cialdini et al. 
1991; De Kort et al. 2008), sustainable transportation (Kormos et al. 2015), recycling (Schultz 1999), and water conservation (Richetin et al. 2016; Schultz et al. 2016; Jaeger and Schultz 2017). Past studies have also showed that social norms can be applied to promote energy conservation in both public (Bator et al. 2014; Bergquist and Nilsson 2016; Dwyer et al. 2015; Oceja and Berenguer 2009) and residential settings (Allcott 2011; Nolan et al. 2008; Schultz et al. 2007; Schultz et al. 2015). However, the effect of normative influence is often moderated by other psychological variables. For example, stating a commitment to save water before receiving normative information about water conservation promotes long-term water saving (Jaeger and Schultz 2017). Similarly, recent meta-analytic reviews suggest that the effect of social influence on sustainable behavior is conditional (Abrahamse and Steg 2013; Fischer 2008). One important condition for social norms to affect behavior is that descriptive social norms (signaling what others do) and injunctive social norms (signaling other peoples (dis)approval) are aligned (Cialdini 2003). That is, socially approved norms affect behavior more effectively if people also observe that other act in accordance with those norms. For example, Cialdini (2003) argued that providing an injunctive anti-litter norm while at the same showing that people litter undermines peoples motivation to avoid littering. Applied to energy usage, norm alignment has shown to be crucial for normative feedback to result in energy conservation (e.g., Schultz et al. 2007). Another factor that may affect conformity to social norms is social comparisons (Festinger 1954). Situations that make people compare themselves to others may also be situations that make people more inclined to adjust their behaviors to others. The present paper applies normative influence to smart meters in order to examine different forms of normative feedback to promote energy conservation. The aims of this paper is first to conceptually replicate the effect of norm alignment (Cialdini 2003; Schultz et al. 2007), suggesting that the impact of social norms will be stronger if people are provided with information that other people both conduct and approve of energy conservation. Second, building on social comparison theory, we aimed to explore if normative feedback is affected by feedback unit (i.e., monetary versus kWh). Finally, also drawing on social comparison theory, we introduce norm distance, a new theoretical proposition suggesting that the impact of social norm depends on "how far" other people's behavior is from our own behavior. More specifically, as social comparisons should increase with increased closeness, we suggest that people are more likely to adjust their behaviors to others if other people save just a little bit more energy than they do than if other people save much more energy.

\section{Theory and hypotheses}

Norm alignment In order to resolve the mixed support for normative influence, Cialdini et al. (1990) differentiated between the descriptive norm, providing information about what other people do, and the injunctive norm, providing information about other people's approval or disapproval. The increased strength of normative influence when aligning descriptive and injunctive norm has both been discussed conceptually (Cialdini 2003) and supported empirically within energy conservation intentions (Smith et al. 2012) and behavior (Schultz et al. 2007, 2015). As a conceptual replication, we hypothesize (H1) that participants will more strongly adjust their intended energy usage to neighbors (e.g., higher conformity to the norm) when social norms are aligned (energy use is low and low is approved) than when social norms are conflicted (energy use is high and low is approved).

Norm distance Past studies on normative influence have found that closeness to the norm source increases conformity. Participants who received a message asking for towel reusage worded as " $75 \%$ of the guests who stayed in this room..." were more likely to reuse their towels than participants asked by the wording " $75 \%$ of the guests..." (Goldstein et al. 2008; Schultz et al. 2008; Reese et al. 2014). It may be that such physical closeness increases conformity because people are more inclined to compare themselves to others when others are closer (physical as well as psychological). According to social comparison theory (Festinger 1954), people are in fact more likely to compare themselves to others if the comparison is not perceived as too extreme. For example, a chess novice is unlikely to compare ones success to a chess master. Based on social comparison theory and in elaboration of research on physical closeness, we suggest that conformity to social norms is moderated by the distance between one's own behavior and the normative behavior. More specifically, we expect that people are more likely to adjust their own behavior to other people's behavior if the difference between their own 
behavior and others' behavior is not too extreme. Therefore, we hypothesize $(\mathrm{H} 2)$ that participants will more strongly adjust their intended energy usage to neighbors (e.g., higher conformity to the norm) when neighbors' energy usage is close to participants' energy usage (e.g., proximal condition) than when far from participants' energy usage (e.g., distal condition).

Feedback unit When evaluating usage of energy meters, consumers have stated that feedback in $\mathrm{kWh}$ is perceived as too abstract (Hargreaves et al. 2010). Social comparison theory predicts that people are more likely to compare themselves with others under uncertainty. Therefore, a less familiar and discernible feedback unit $(\mathrm{kWh})$ may promote stronger social comparison tendencies than a more familiar feedback unit (monetary). We therefore hypothesize $(\mathrm{H} 3)$ that feedback provided in $\mathrm{kWh}$ will promote stronger adjustments in intended energy usage (e.g., higher conformity to the norm) than when monetary $\left(\mathrm{SEK}^{1}\right)$ feedback is used.

\section{Study 1: method}

In study 1 , the role of norm alignment, norm distance, and feedback unit in normative information to promote energy usage intentions was examined in a laboratory experiment, using fictive smart meters.

Participants Four hundred eighty individuals enrolled at the participant pool at the Department of Psychology University of xxxxxxx, xxxxx, were contacted and offered to participate in a psychology Study. A total of 110 individuals participated in the experiment and received a monetary pay off of 50 SEK (approximately 6 USD). Six participants were excluded due to misunderstanding of the instructions, leaving 104 participants $(66.3 \%$ female, age $19-55, \mathrm{M}=28.2$ years) for the analysis.

Procedure and design Participants were seated in front of a computer in a private room and instructed to imagine that the stimulus material was an application installed on their smartphone, proving feedback on their private and their neighbor's household energy usage for the last month. Feedback was provided in either kWh or monetary feedback (SEK) in five energy usage scenarios.

\footnotetext{
$\overline{1}$ Swedish kronor.
}

Feedback on participant's private energy usage was held constant at 250 across all conditions, providing a baseline through with participants compared their own usage to neighbor's usage in five scenarios. The design was a 5 (neighbors energy use: 50 vs. 150 vs. 250 vs. 350 vs. $450) \times 2$ (feedback: kWh vs. SEK) mixed design with between-subject measures on the last condition.

In order to test the conflicted versus congruent norm alignment conditions, the stimulus material included both a descriptive and an injunctive norm. The descriptive norm displayed neighbor's energy usage: 50, 150, 250, 350, and 450 (in $\mathrm{kWh}$ or SEK). The injunctive norm was operationalized via three fields: aimed to signal what was approved (green field), what was disapproved (red field), and a neutral condition (yellow field). The stimulus material thus included two congruent norm alignment conditions (50 and 150), two conflicted norm conditions (350 and 450), and one neutral condition (250). In all conditions, participant's own energy usage was held constant at 250 .

Study 1 was designed to test the norm distance effect, predicting that conformity to social norms will depend on how close or far others' behaviors are from one's own behavior. Study 1 compared two proximal norm distances, where participants' behavior was close to neighbors' behaviors (participants $=250$ vs. neighbors $=$ 150 and participants $=250$ vs. neighbors $=350$ ), to a distal norm distance condition, where this difference was greater (participants $=250$ vs. neighbors $=50$ and participants $=250 \mathrm{vs}$. neighbors $=450$ ).

In brief, study 1 aimed to explore three potential moderators of normative influence: norm alignment, norm distance, and feedback unit. In a repeatedmeasure design, participants were randomly provided with five fictive energy usage scenarios in one of two feedback conditions, displaying the following: (1) congruent distal norm: neighbors using extremely less energy than participants. (2) Congruent proximal norm: neighbors using a just a little bit less energy than participants. (3) Control condition: neighbors using as much energy as the participants. (4) Conflicted proximal norm: neighbors using just a little bit more energy than participants. (5) Conflicted distal norm: neighbors using extremely more energy than participants (see Fig. 1). As a measure of conformity to normative information, participants were asked about their intentions for future energy conservation "How much energy do you intend to use for the next month?" on a 0-500 scale. Finally, as a manipulation check, participants were asked "How would you 


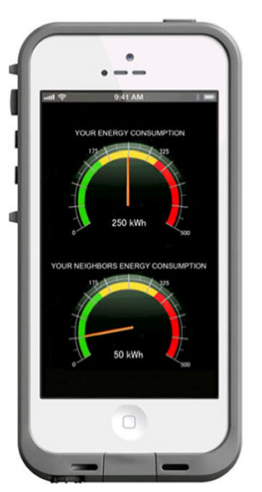

Congruent distal

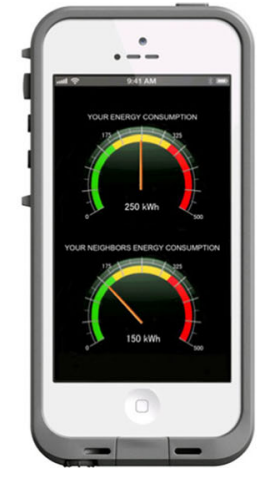

Congruent proximal

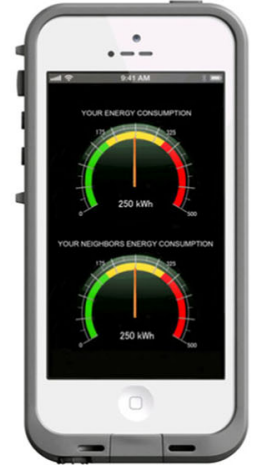

Control condition

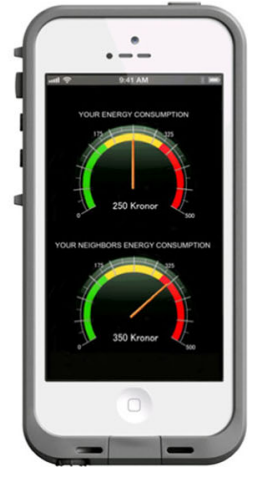

Conflicted proximal

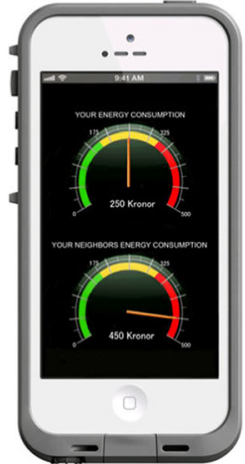

Conflicted distal
Fig. 1 Five smart meter scenarios provided participants with fictive normative information. The upper scale of the stimulus material reads "your energy consumption" and was held constant

describe the difference in energy usage between you and your neighbor's". A four-point scale ranging from 1 "No difference" to 4 "Extremely large difference" was used to measure participant's perception of the difference between own and neighbor's energy usage.

\section{Study 1: results and discussion}

Manipulation check In order to examine the norm distance measure, a one-way analysis of variance (ANOVA) on ratings of difference between participants' and neighbor's energy usage was conducted. The results showed a significant difference between the conditions $(F(3$, $101)=208.8, p \leq .001)$. Bonferroni post hoc tests first showed that all norm conditions were perceived to differ from the control condition (all $p$ 's $<.001$ ). Furthermore, the difference in energy usage between participants and neighbors was perceived as larger in both distal conditions than the two proximal conditions (all $p$ 's $<.001$ ).

Main analysis Before conducting the main analysis, we calculated the difference between participant's energy usage intentions and the stated energy usage of neighbors in each condition. Hence, as a measure of conformity to social norms, we calculated how much participants adjusted their energy usage intentions to the neighbors' energy usage, where 0 indicates complete adjustment. To control for order effect of the stimulus material, five one-way ANOVAs were conducted (one for each at 250 (kWh or SEK). The lower scale reads "your neighbor's energy consumption" and was varied from 50 to 450 (kWh or SEK)

of the stimulus material presented in Fig. 1). The results showed no significant effect of order (all $p$ 's $>.05$ ).

As a main analysis, we conducted a 5 (normative information: congruent distal vs. congruent proximal vs. control vs. conflicted proximal vs. conflicted distal) $\times 2$ (feedback unit: kWh vs. SEK) ANOVA with repeated measures on the first condition on adjusted energy usage intentions. Results revealed a main effect of normative information $(F(1.5,102)=448.77$, $\left.p<.001, \eta_{p}{ }^{2}=.82\right)$. Simple slope analysis supported hypothesis 1 , showing that participants adjusted their energy usage intentions more when provided with congruent normative information compared to when provided with conflicted normative information (all $p$ 's $<.001$ ). In support of hypothesis 2 , pairwise comparison results also showed that all norm conditions differed significantly (all $p$ ' $<.05$ ) and that the strongest adjustment of energy usage intentions was found in the proximal congruent norm condition. When testing for hypothesis 3, no significant interaction was found $(F(1.5$, $\left.102)=1.5, p=23, \eta_{p}{ }^{2}=.015\right)$, suggesting that adjustments in energy usage intentions were not affected by feedback unit Fig. 2.

Discussion In line with past research (e.g., Smith et al. 2012), we found that people are more likely to adjust their intentions to social norms when the norms are congruently aligned. That is, people are more likely to adjust their behavior to others when others are conducting an approved (rather than an unapproved) behavior (see Cialdini 2003 for a discussion). In addition to this conceptual replication, the present study 1 


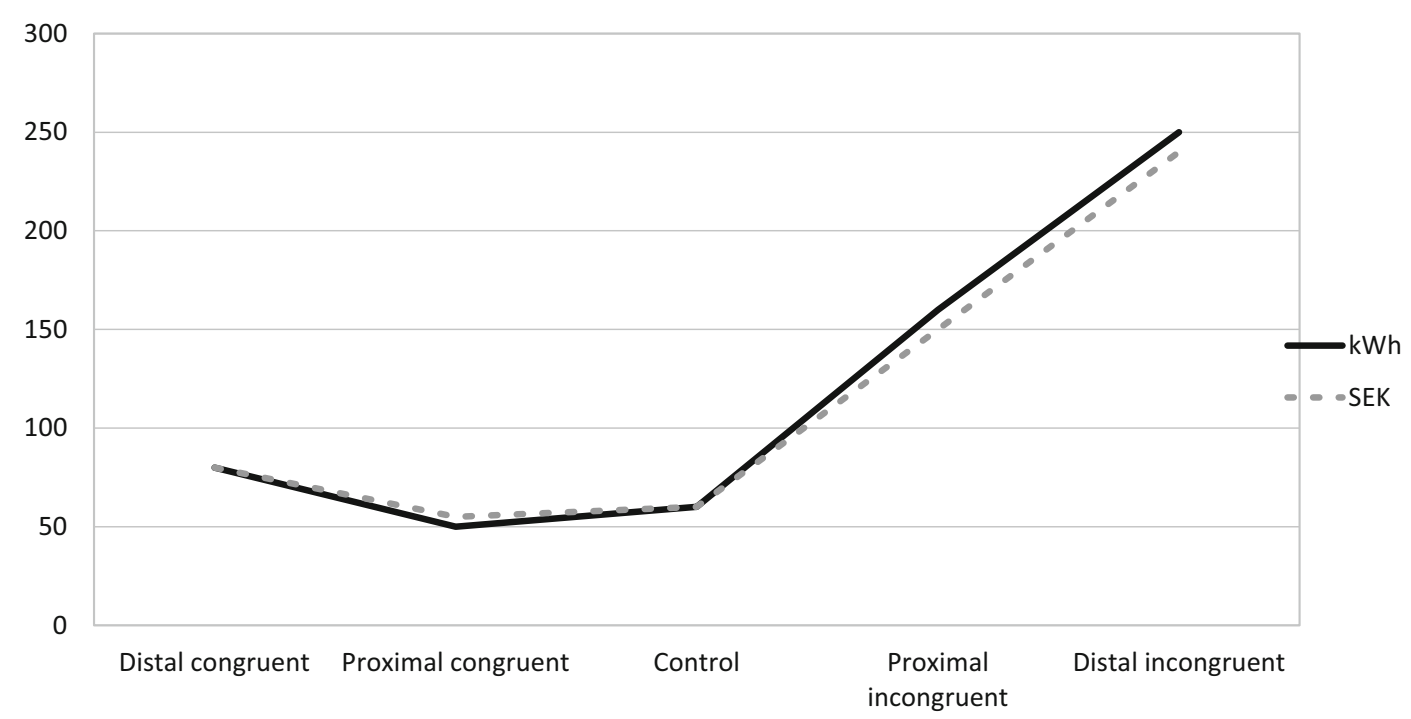

Fig. 2 Adjusted energy usage intentions to neighbors as a function of norm alignment and norm distance. 0 indicates that participants fully adjusted their energy usage intentions to neighbors' energy usage, hence completely conformed to the social norm

also wanted to test a norm distance hypothesis. We suggested that people are more likely to adjust their behavior to others when others' behaviors are not too extreme. Study 1 supported our hypothesis, showing that adjustments to other people's energy usage were strongest when other people's behavior was proximal to participant's behavior.

\section{Study 2: theory and method}

Study 2 aims to further explore the norm distance effect found in study 1 . One limitation of study 1 was the dichotomous operationalization of norm distance. Therefore, study 2 includes five norm distance conditions in order to test a more refined norm distance effect and if the norm distance effect is linear.

Norm distance is one dimension of the descriptive norm, answering the question "how much others are performing behavior A." There are, however, other means to improve the influential power of the descriptive norm. For example by manipulating the frequency of descriptive norm, as demonstrated by Milgram et al. (1969), showing that the number of by passers that looked at an empty spot in the sky increased with increased group size looking at that empty spot. Previous studies within environmental psychology have found higher frequencies of descriptive norm to increase pro-environmental intentions in both experimental (Von Borgstede et al. 1999) and field settings (Kormos et al. 2015). The frequency of descriptive norm therefore answers the question "how many others are performing behavior A." The second aim of study 2 was to compare the norm distance effect to the frequency of descriptive norm. If the norm distance effect holds over different levels of frequency of descriptive norm, it would suggest that norm distance and frequency of descriptive norms are two distinct means to increase the influential power of the descriptive norm.

Design Study 2 used the same scenario design as in study 1; however, the stimulus material was modified into a 5 (norm distance: 25 vs. 75 vs. 125 vs. 175. vs. 225 ) $\times 3$ (frequency of descriptive norm: 20 vs. $80 \%$ vs. control) mixed-design with repeated-measures on the first condition). In all conditions, participant's energy usage was held constant at 250 . In the between-group condition, respondents were randomly assigned to one of the three frequencies of descriptive norm conditions, stating that the energy usage provided information about the following: "...20\% of your neighbors" in the lowfrequency condition, “...80\% of your neighbors", in the high-frequency condition, and “...your neighbors" in the control condition.

A web survey was mailed to 300 students recruited from the University of xxxx. A total of 142 respondents completed the survey, 16 participants were excluded due to 
incomplete answers, and 4 were excluded due to difficulty in understanding the study, leaving 122 participants $(79.7 \%$ female, age $19-56, M=27.8$ years) for the analysis.

\section{Study 2: results and discussion}

Main analysis As in study 1, an index variable for adjusted energy usage intentions was created, where 0 indicates complete adjustment. A one-way ANOVAs tested for order effects found no significant differences on ratings of energy usage intentions (all $p$ 's $>.05$ ). As a main analysis, we conducted a 5 (norm distance: 25 vs. 75 vs. 125 vs. 175 vs. 225 ) $\times 3$ (frequency of descriptive norm: 20 vs. $80 \%$ vs. control) mixed-design ANOVA with repeated measures on the first condition on adjusted energy usage intentions.

Results revealed a significant main effect for norm distance $\left(F(2.8,119)=62.1, p<.001, \eta_{p}{ }^{2}=.34\right)$. Simple slope analysis showed that all norm distance conditions differed significantly (all $p$ 's $>.01$ ), except for condition 225 and $125(p=.25)$. Tests of within-subjects contrast revealed that the relation is best explained by a linear trend $\left(F(1,119)=81.4, p \leq .001, \eta_{p}{ }^{2}=.41\right.$ ), as expected (see Fig. 3). Furthermore, results showed that the norm distance effect was not significantly moderated by frequency of descriptive norm $(F(4.37,119)=0.83, p=.51)$.

Discussion Although the results were best explained by a linear function, the simple slope analysis showed that the most proximal condition did not differ significantly from the condition in between the most proximal and most distal condition. The inverted u-shape between the 225,175 , and the 125 condition was not predicted by social comparison theory. However, in general, the results of study 2 once again showed that people adjust their intentions more strongly when other people's behaviors are more proximal than when other people's behavior are more distal, supporting the norm distance effect.

\section{General discussion}

Since energy production is dominated by fossil fuels causing substantial $\mathrm{CO}_{2}$ emissions, and since research suggests that private sphere behavioral change can be achieved relatively easy (Dietz et al. 2009), it is important to investigate ways to provide effective tools for individuals and households to facilitate this change. Providing normative feedback is a promising such tool, but how should this feedback be given in order to be as efficient as possible in motivating behavioral change? Just at novices are unlikely to compare their performance to experts, we proposed that people are more influenced by others with proximal levels of a behavior. Based on social comparison theory, predicting that people are more likely to compare themselves to other when other people's behaviors are not perceived as too extreme, we hypothesized that normative feedback will be most influential when other people's behaviors are not "too far" from one's own behavior. Two studies examined this norm distance effect as a moderator in normative influence applied to household energy usage. In general, both studies supported the norm distance effect.

As a conceptual replication, study 1 first found that people adjust their behavioral intentions to others in greater degree when provided with congruent normative feedback. That is, when descriptive and injunctive norms are aligned, signaling that other people engage in the approved (rather than disapproved) behaviors. More specifically, study 1 showed that normative influence affected energy usage intentions when descriptive and injunctive norms were congruently aligned (when neighbors were doing what was approved). In the conflicted norm conditions (when neighbors were doing what was disapproved), participants did not adjust their behaviors more than in the control condition.

Second, study 1 tested of a new concept, norm distance, revealing "how much other people are doing", as a special case of the descriptive norm. Results showed that norm distance influenced energy usage intentions. This suggests that, in addition to norm alignment, norm distance adds further influential power to the normative information. Our third hypothesis was not supported. Instead, results showed that the effect of norm distance was not affected by feedback unit. This finding is, however, interesting and may suggest that norm-based feedback motivates behavioral change when using both monetary and kHw.

Study 2 once again supported a main effect of norm distance in a congruent norm alignment condition. Results showed that people are more likely to adjust their behavioral intentions to others if others' behaviors are closer to one's own behavior than if others' behaviors are far from one's own behavior. Moreover, study 2 tested if frequency of descriptive norm (number of 


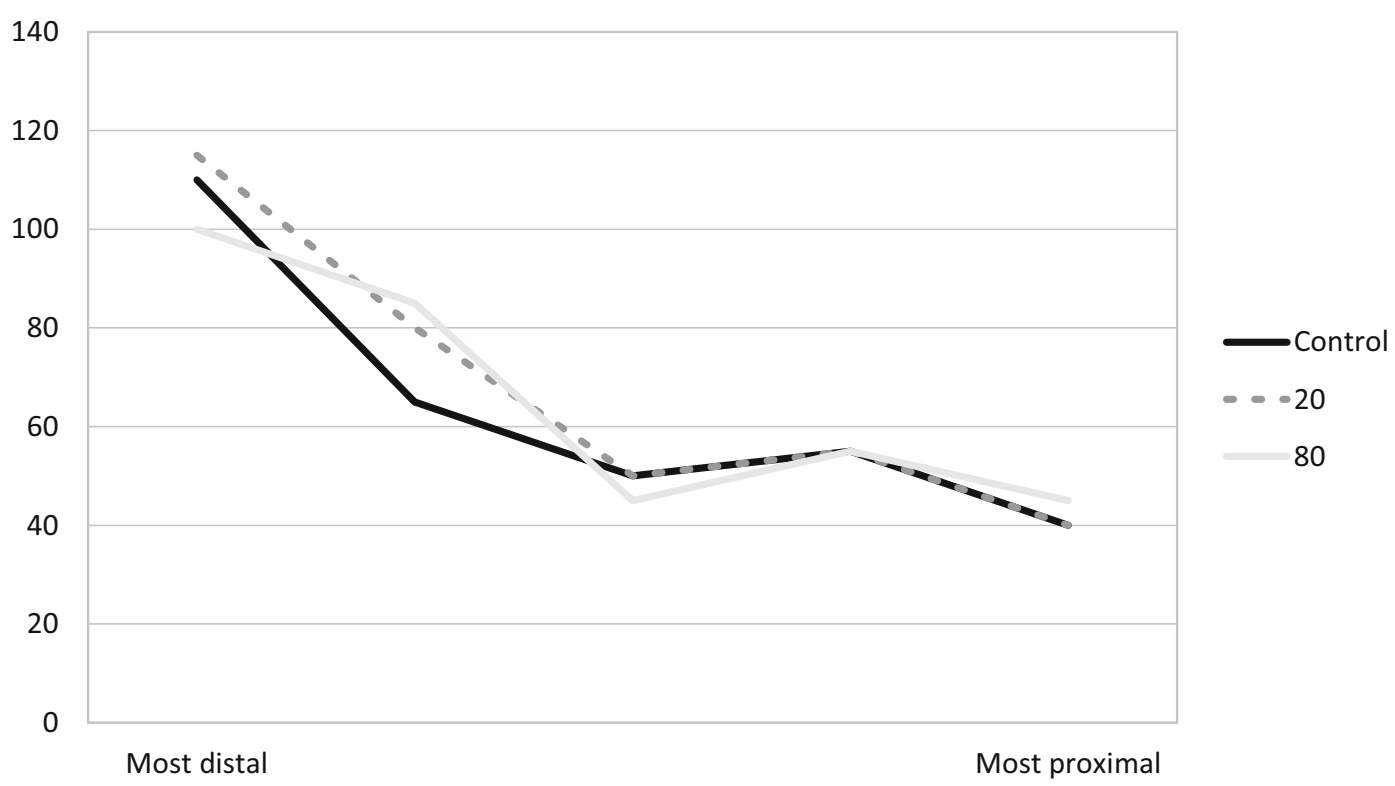

Fig. 3 Adjusted energy usage intentions to neighbors as a function of norm distance and frequency of descriptive norms. 0 indicates that participants fully adjusted their energy usage intentions to neighbors' energy usage, hence completely conformed to the social norm

neighbors conducting the described behavior) affects the influential power of norm distance. Results showed no moderating effect of frequency of descriptive norm. In the context of application to energy conservation feedback, the studies support the effect of norm alignment in social influence. Building on these findings, the present results suggest that norm distance could further increase the influential power of social norms.

A few limitations concerning the studies should be noted. First, debriefing revealed that the norm manipulation in study 1 was transparent. Although this might be seen as a threat to validity, ANOVA's testing for order effects did not find significant differences between the orders in with norm conditions was presented. Showing that responses to the condition presented first (when respondents were unaware of the four additional conditions to come) did not differ significantly from subsequent responses. This suggests that energy usage intentions were not affected by the repeated-measures design. Second, both study 1 and study 2 measured intentions for energy usage. Although past meta-analyses have found a medium to large intention-behavior correlations (Armitage and Conner 2001; Kormos and Gifford 2014) and have used intentions to evaluate processes of normative influence (Smith et al. 2012), these results should be validated using actual energy conservation behaviors. Moreover, it should be noted that the data varied in intention between the conditions, suggesting that participants did not simply report maximum (or minimum) energy conservation intentions over conditions. Norm alignment and norm distance both explain a medium to large amount of that variance. Third, the injunctive norm was only manipulated to approve of low energy usage; an aligned norm condition where high energy usage was approved was not tested. From a theoretical perspective, the injunctive norm should have been varied in order to investigate the independent effects; this can be seen as a limitation. However, the present design could also reflect an ecological valid operationalization of the injunctive norm, given that most people actually approves of low rather than high energy usage. Fourth, both our experiments tested students in within-subject designs, limiting the external validity and may have inflated the effects. Finally, although the external validity of the present study might have been limited by focusing respondents on energy conservation, these findings are not to be seen as absolute numbers of energy conservation in private households, but rather as an attempt to experimentally examine moderators for normative influence to affect energy conservation.

Conclusion Building on past research demonstrating that conformity to social norms is influenced by norm alignment, the present research proposed that the impact of normative influence is moderated by norm distance. In 
essence, the norm distance displays the distance between one's own behavior and others' behavior, proposing that people are more influenced by others with proximal levels of a behavior. Hence, according to the norm distance effect, "how much others are doing" will moderate the influential power of social norms. In line with predictions derived from social comparison theory, both studies 1 and 2 found that conformity increased when others' behaviors are more proximal to one's own behavior.

The applied implications of the studies concern ways of improving normative feedback to promote households' energy conservation. This feedback can be provided via phone applications, via homepages, or using in-home displays. By using a theory-driven approach to the design of the feedback, the application in different contexts should be facilitated. These theoretical findings concern the importance of norm alignment. That is, people are more influenced by the normative information if others are acting according to what is approved. In addition, the norm distance further increases adjustments in intended energy conservation. That is, the influential power of social norms increased as other people's behavior came closer to participants' own behavior. We call this the norm distance effect.

\section{Compliance with ethical standards}

Conflict of interest The authors declare that they have no conflict of interest.

Open Access This article is distributed under the terms of the Creative Commons Attribution 4.0 International License (http:// creativecommons.org/licenses/by/4.0/), which permits unrestricted use, distribution, and reproduction in any medium, provided you give appropriate credit to the original author(s) and the source, provide a link to the Creative Commons license, and indicate if changes were made.

\section{References}

Abrahamse, W., \& Steg, L. (2013). Social influence approaches to encourage resource conservation: a meta-analysis. Global Environmental Change, 23, 1773-1785.

Abrahamse, W., Steg, L., Vlek, C., \& Rothengatter, T. (2005). A review of intervention studies aimed at household energy conservation. Journal of Environmental Psychology, 25(3), 273-291.

Allcott, H. (2011). Social norms and energy conservation. Journal of Public Economics, 95, 1082-1095.

Armitage, C. J., \& Conner, M. (2001). Efficacy of the theory of planned behaviour: a meta-analytic review. British Journal of Social Psychology, 40, 471-499.
Bator, R. J., Tabanico, J. J., Walton, M. L., \& Schultz, P. W. (2014). Promoting energy conservation with implied norms and explicit messages. Social Influence, 9(1), 69-82.

Bergquist, M., \& Nilsson, A. (2016). I saw the sign: promoting energy conservation via normative prompts. Journal of Environmental Psychology, 46, 23-31.

Cialdini, R. B. (2003). Crafting normative messages to protect the environment. Current Directions in Psychological Science, 12(4), 105-109.

Cialdini, R. B., \& Trost, M. R. (1998). Social influence: social norms, conformity, and compliance. In D. T. Gilbert, S. T. Fiske, \& G. Lindzey (Eds.), The Handbook of Social Psychology (Vol. 2, pp. 151-192). Boston: McGraw-Hill.

Cialdini, R. B., Reno, R. R., \& Kallgren, C. A. (1990). A focus theory of normative conduct: recycling the concept of norms to reduce littering in public places. Journal of Personality and Social Psychology, 58, 1015-1026.

Cialdini, R. B., Kallgren, C. A., \& Reno, R. R. (1991). A focus theory of normative conduct: a theoretical refinement and reevaluation of the role of norms in human behavior. Advances in Experimental Social Psychology, 24, 201-233.

De Kort, Y. A. W., McCalley, L. T., \& Midden, C. J. H. (2008). Persuasive trash cans: activation of littering norms by design. Environment \& Behavior, 40, 870-891.

Dietz, T., Gardner, G. T., Stern, P. C., \& Vandenbergh, M. P. (2009). Household actions can provide a behavioral wedge to rapidly reduce US carbon emissions. Proceedings of the National Academy of Science of the United States of America, 106, 18425-18456.

Dwyer, P. C., Maki, A., \& Rothman, A. J. (2015). Promoting energy conservation behavior in public settings: the influence of social norms and personal responsibility. Journal of Environmental Psychology, 41, 30-34.

Festinger, L. (1954). A theory of social comparison processes. Human Relations, 7, 117-140.

Fischer, C. (2008). Feedback on household electricity consumption: a tool for saving energy? Energy Efficiency, 1, 79-104.

Goldstein, N. J., Cialdini, R. B., \& Griskevicius, V. (2008). A room with a viewpoint: using social norms to motivate environmental conservation in hotels. Journal of Consumer Research, 35, 472-482.

Hargreaves, T., Nye, M., \& Burgess, J. (2010). Making energy visible: a qualitative field study of how householders interact with feedback from smart energy monitors. Energy Policy, 38(10), 6111-6119.

Jaeger, M. J., \& Schultz, P. W. (2017). Coupling social norms and commitments: testing the underdetected nature of social influence. Journal of Environmental Psychology, 51, 199-208.

Karlin, B., Zinger, J. F., \& Ford, R. (2015). The effects of feedback on energy conservation: A meta-analysis. Psychological Bulletin, 141(6), 1205-1227.

Kormos, C., \& Gifford, R. (2014). The validity of self-reported measures of proenvironmental behavior: a meta-analytic review. Journal of Environmental Psychology, 40, 359-371.

Kormos, C. \& Gifford, R., \& Brown, E. (2015). The influence of descriptive social norm information on sustainable transportation behavior: a field experiment. Environment and Behavior, 1-23. https://doi.org/10.1177/0013916513520416.

Milgram, S., Bickman, L., \& Berkowitz, O. (1969). Note on the drawing power of crowds of different size. Journal of Personality and Social Psychology, 13, 79-82. 
Morris, M. W., Hong, Y., Chiu, C., \& Liu, Z. (2015). Normology: integrating insights about social norms to understand cultural dynamics. Organizational Behavior and Human Decision Processes, 129, 1-13.

Nolan, J. M., Schultz, P. W., Cialdini, R. B., Goldstein, N. J., \& Griskevicius, V. (2008). Normative social influence is underdetected. Personality and Social Psychology Bulletin, 34, 913-923.

Oceja, L., \& Berenguer, J. (2009). Putting text in context: the conflict between pro-ecological message and anti-ecological descriptive norms. The Spanish Journal of Psychology, 12(2), 657-666.

OECD/IEA. (2016). http://www.iea.org/media/statistics/Recent_ Trends in the OECD.pdf

Reese, G., Loew, K., \& Steffgren, G. (2014). A towel less: social norms enhance pro-environmental behavior in hotels. The Journal of Social Psychology, 154(2), 97-100.

Richetin, J., Perugini, M., Mondini, D., \& Hurling, R. (2016). Conserving water while washing hands: the immediate and durable impacts of descriptive norms. Environment and Behavior, 48(2), 343-364.

Schultz, P. W. (1999). Changing behavior with normative feedback interventions: a field experiment on curbside recycling. Basic and Applied Social Psychology, 21(1), 25-36.
Schultz, P. W., Nolan, J. M., Cialdini, R. B., Goldstein, N. J., \& Griskevicius, V. (2007). The constructive, destructive, and reconstructive power of social norms. Psychological Science, $18,429-434$.

Schultz, P. W., Khazian, A. M., \& Zaleski, A. C. (2008). Using normative messages to promote conservation among hotel guests. Social Influence, 3(1), 4-23.

Schultz, P. W., Estrada, M., Schmitt, J., Sokoloski, R., \& SilvaSend, N. (2015). Using in-home displays to provide smart meter feedback about household electricity consumption: a randomized control trial comparing kilowatts, cost, and social norms. Energy, 90, 351-358.

Schultz, P. W., Messina, A., Tronu, G., Limas, E. F., Gupta, R., \& Estrada, M. (2016). Personalized normative feedback and the role of personal norms: a field experiment to reduce residential water consumption. Environment and Behavior, 48(5), 686-710.

Smith, J. R., Louis, W. R., Terry, D. J., Greenaway, K. H., Clarke, M. R., \& Cheng, X. (2012). Congruent or conflicted? The impact of injunctive and descriptive norms on environmental intentions. Journal of Environmental Psychology, 32, 353-361.

Von Borgstede, C., Dahlstrand, U., \& Biel, A. (1999). From ought to is: moral norms in large-scale social dilemmas. Göteborg Psychological reports, 29, 1-17. 